\title{
COMPOSITIONAL AND STRESS STATE CHARACTERIZATION OF TECHNICAL ALLOYS USING THERMOPOWER AND COERCITIVITY MEASUREMENTS
}

\author{
Attila SZABO ${ }^{*}$, Ladislav NOVAK ${ }^{* *}$, Antal LOVAS* \\ *Department of Vehicles Manufacturing and Repairing, Budapest University of Technology and Economics, Bertalan L. 2. 1111 \\ Budapest, Hungary \\ ** Department of Physics, Faculty of Electrical Engineering and Informatics, Technical University of Košice, Park Komenského 2, \\ 04200 Košice, Slovak Republic
}

\begin{abstract}
The thermopower (S) measurement is proposed as an acceptable method after a suitable calibration for the study of compositional and structural (phase related) factors, to determine a level of heat treating or even the level of internal stress state in engineering alloys. We are focusing on to determine the influence of various Ni content in FeNi alloy system both in amorpus and in crystalline state. We also define the influence of mechanical and surface stress from the point of view of thermopower. The results of thermoelectric power measurements reported in this paper do confirm the applicability of $S(T)$ measurements in the determination of compositional effects and mapping the stress state in different type of engineering alloys.
\end{abstract}

Keywords: thermopower, TEP, microhardness, amorphous, stress, heat treating

\section{INTRODUCTION}

The localization of defects -which frequently appear as microscopic crack formation- in work pieces has great practical interest [1].

In the present paper a complex study is proposed, where thermopower and static coercive force testing, as well as micro hardness measurements were performed, and the results are compared. On this basis the very early state of damage evolution can be recognized.

Among the mentioned measuring methods, the thermopower (TEP) characterization seems to be especially promising. The description of these measurements can be found in more detail in Ref. [2,3].

Despite of the cited results, and also the technical simplicity of this measurement, it is not popular among the non-destructive material testing methods.

The probable reason of this is the complicate interaction between the factors like chemical composition, phase relations, internal stress level and surface deformation, which are individually contribute to the development of the actual magnitude of the thermopower being experimentally measured. In the previous reports it was found, that the absolute value and the sign of $\mathrm{S}$ are influenced mainly by the chemical compositions and the phase relations in the sample. The influence of ageing is also reported in Ref [2].

\section{EXPERIMENTAL}

In our experiments Fe based Fe-Ni alloys (crystalline and amorphous phase) were applied to reveal the connection between the evaluation of thermopower and the alloy composition and the phase relations as well. For this purpose, the TEP are determined versus the $\mathrm{Ni}$ content both in the crystalline and also in the glassy state. The glassy state has inherently single phase nature, so we can separate the contribution arising from the coexistence of several phases. As the glass is a single phase matter, the compositional change (varying $\mathrm{Ni}$ content) does reflect solely the contribution arising from the electron density in the evolution of TEP. The crystalline Fe-Ni alloys are especially suitable for the outlined concept. As a variety of phase relations can be produced by heat treatments. The additional motivation that plenty of references exist concerning to the phase transformations in the above mentioned alloys.

Commercial C45 steels as well as amorphous Fe-B alloys were also used for TEP measurements under mechanical stress. The details of thermopower, static coercivity, surface roughness, as well as microhardness measurements are reported in Refs. [5-7].

\section{RESULTS AND DISCUSSION}

It was reported previously, that $\mathrm{S}(\Delta \mathrm{T})$ can supply information from the electronic structure of the investigated metals and alloys. In addition $S(\Delta T)$ is also related with the characteristic feature of the $\mathrm{M}-\mathrm{Cu}$ phase diagram $(\mathrm{Cu}$ is the applied electrode material during the measurement). It is expected therefore, that $\mathrm{S}(\Delta \mathrm{T})$, is also sensitive to the existence of allotropes either in the investigated $\mathrm{M}$ metal or in the alloy, which can exhibit phase transitions either with or without compositional change.

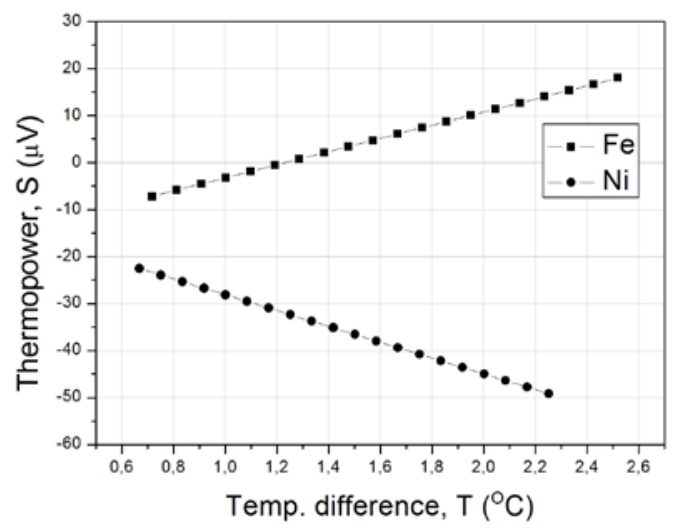

Fig. 1 TEP of Fe and Ni metals

The detailed explanation of Fig 1. can be found in Ref. [6]. To understand, why does the TEP curve have the 
above visible shape, the $\mathrm{Cu}-\mathrm{M}$ phase diagram gives the answer:

It was found, that the slope of the $S(T)$ curve is negative, when $\Delta G_{(\mathrm{M}-\mathrm{Cu})} 0$, i.e the heat of mixing is nearly no-zero, (but negative) This is the case of the formation of continuous series of solid solutions between two elements. In these interactions the heat of alloy formation is negligible; consequently, the contribution of entropy becomes significant in the total free energy change at mixing. These types of phase diagrams often exhibit ordering or the formation of intermetallic compound-like phases at low temperatures.

Opposite to the previously outlined cases, another types of slopes are positive. This type of behaviour can be observed, when the mutual solubility between $\mathrm{Cu}$ and $\mathrm{M}$ is limited at low temperatures (in phases, stable at low temperatures) but increasing with rising temperature. The heat of mixing is substantial and negative in such interactions $\left(\Delta \mathrm{G}_{(\mathrm{M}-\mathrm{Cu})}<0\right)(\mathrm{Cd}, \mathrm{Fe}, \mathrm{Ti})$. The appropriate phase diagrams are usually eutectic, with intermetallic compounds.

Because of the well-known phase relation, in the following examinations an Fe-Ni alloy system (both in crystalline and in amorphous state) was investigated to reveal the connection between the $\mathrm{Ni}$ content and the evaluation of thermopower.

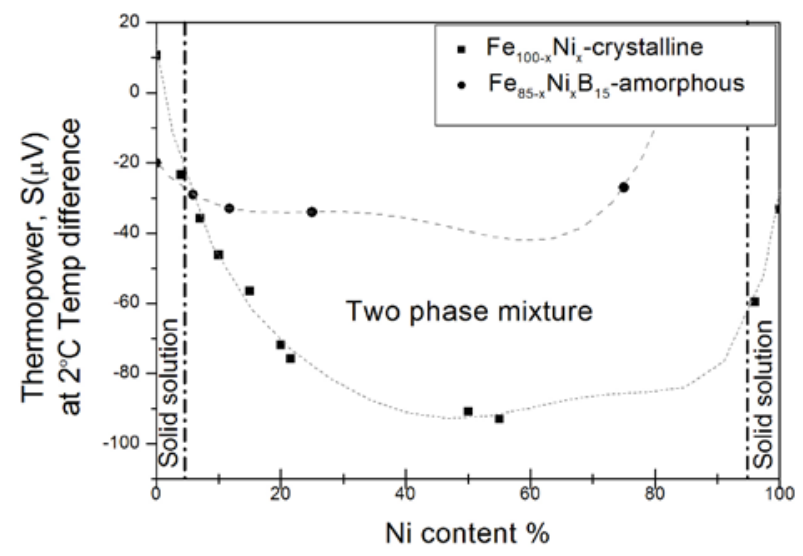

Fig 2 The evaluation of thermopower in the case of crystalline and amorphous state alloys at 2C temp difference

It was found, that the S composition curve exhibits a minimum at around the formation of $\mathrm{FeNi}_{3}$ compound phase. It is interesting to note, that the shape of the curve resembles to the character of heat of mixing curve in the same system. It is also remarkable, that the concentration dependence of electrical resistance also exhibit maximum at around these concentration range [8]. This behaviour is also typical for solid solutions.

The first remarkable trend in the $\mathrm{S}(\mathrm{T})$ curves is the pronounced slope in the diluted concentration regime on Fe-Ni crystalline curve. Close to the pure Fe region, three points-including the pure Fe- lies in the ferrite range (bcc solid solution), in which the $\mathrm{S}$ drops rapidly with the concentration (solid solution). At the opposite (Ni) side the slope of $\mathrm{S}(\mathrm{T})$ curve is less steep and -opposite to the Fe-side-starts from negative value (pure $\mathrm{Ni}$ ). So in the diluted region the alloying effect is not symmetric: it means, that alloying effect in the fcc or in bcc solid solution is not equally strong even in the case of the identical alloying partners.

It is also important to understand the difference between the thermopower of amorphous and crystalline phase at nearly the same composition.

The value of $\mathrm{S}$ is composed by the density of occupied electron state at the Fermi level and also depends on the Fermi energy, which has a crystal structure dependence. In the single phase region the electron density (which is mostly determined by the concentration of solute element) has a dominant role.

In the case of crystalline state, the fcc-bcc transformation causes a shift in the number of electrons beyond the valence band. Heating the lattice up, different number of electron is able to step into the valence band in case of fcc and bcc lattice, which also will be manifested in the evaluation of thermopower.

In contrast to crystalline state, amorphous alloys have a different electron state density. The spikes in the electron state densities are disappeared, and with increasing $\mathrm{Ni}$ content there is no significant jump in the electron state densities around the Fermi level, because of the absence of phase transitions.

\subsection{Influence of internal and external stresses}

It is well known, that the hardness of Fe and the lowalloyed carbon steels (Fe-C alloys mainly with pearlitic structure) increases either by cold working (work hardening) or via rapid quenching (quench-hardening). Although, both types of hardening are bulk effects, their mechanisms are different. The origin of work hardening is essentially a dislocation pile up mechanism. In contrast, the quench hardening is inducted by phase transformations (martensite phase formation) where the generated internal stress is responsible for the hardness increase.

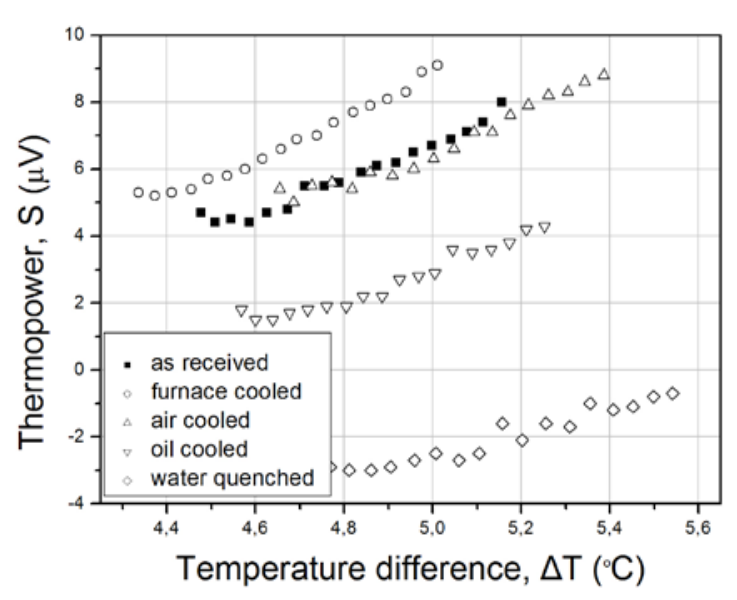

Fig3 Influence of heat treatment on the evaluation of thermopower in C45 steel [5]

The thermopower shift demonstrates clearly the simultaneous contribution of phase transformation and the stress level increase in the quench hardening process (see Fig. 3). 


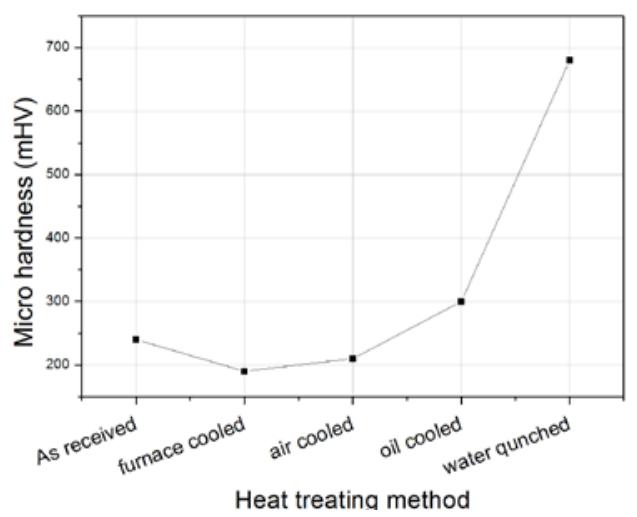

Fig. 4 The evaluation of micro hardens versus the cooling rate in C45 steel

The same change in the bulk stress state is clearly reflected in the trend of micro hardness values, measured on the same sample (see Fig. 4). In this case, the resulting $\mathrm{S}$ change (gradual shift to negative direction), is a result of two effects: phase transformation and induced stresses.

\subsection{The relation between the hardness and thermopower changes due to the surface stress accumulation}

In order to separate the factors arising from the phase transformations and stress accumulation, surface sliding were performed on the same, normalized C45 steel samples.

Both the thermopower measurements and micro hardness tests were carried out along the wear track. The degree of wear was gradually increased and quantified by the scratch number (50-small; 150-medium; 1000-large wear track).

As the wear track increases, the $\mathrm{S}(\Delta \mathrm{T})$ shifts also in negative direction (Fig. 5), but unlike the trends, which is visible in Fig. 3, where only phase taransformations were performed, on Fig. 5 the change of the slope for the individual curves is the pronounced effect. Strong divergence is typical in this case.

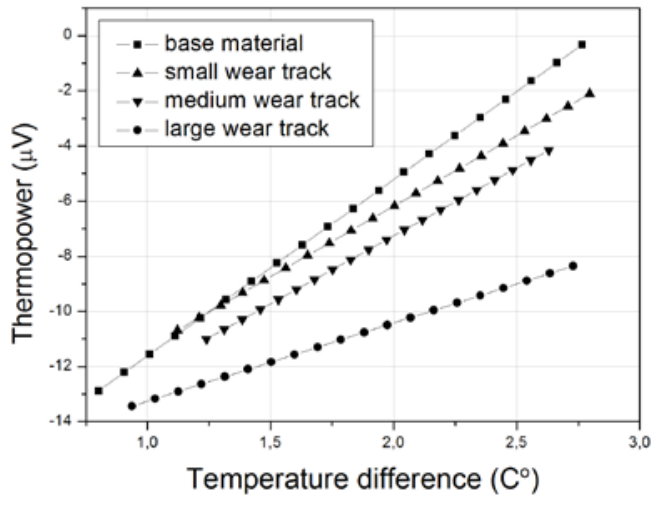

Fig. 5 Thermopower characteristics of C45 samples with increasing wear degrees

Here the dislocation pile up is the dominant mechanism being responsible for the $S(\Delta T)$ change in this case. This fact is supported by the microhardness measurements. The evaluation of micro hardness in the wear track is illustrated in Fig.6.

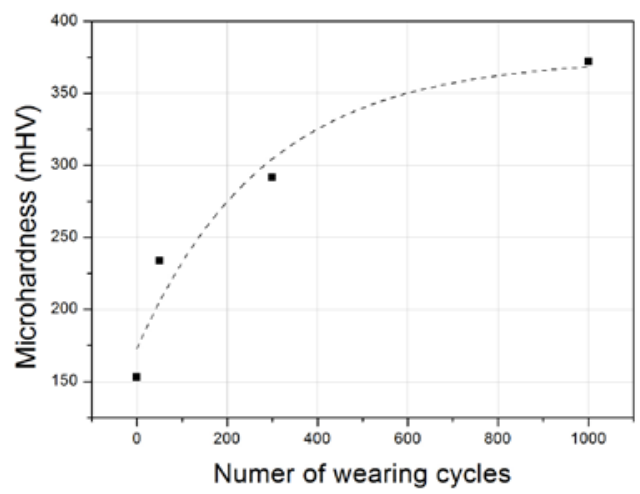

Fig. 6 The evaluation of microhardness versus the wearing cycles in C45 steel

\subsection{The coercivity increase in the surface layer prior to the initial period of crack formation}

As it is shown in Ref. [1], cracks can be developed in the surface layer due to work hardening. Simultaneous $H_{c}$ increase can be detected in the cross section of the sample, depending on the rate of degradation. Again, the work hardening can also be supported by hardness measurements, which was also performed on the crosssectional area of the sample. Visible structural change can also be detected in the vicinity of the surface along the rolling track. In the surface layer a simultaneous increase in static coercive force also can be seen (see Fig. 7).

Fig. 8 shows, that simultaneously with increasing $\mathrm{H}_{c}$ and microhardness values (Fig. 7), there is a negative $\mathrm{S}(\Delta \mathrm{T})$ shift in the thermopower.

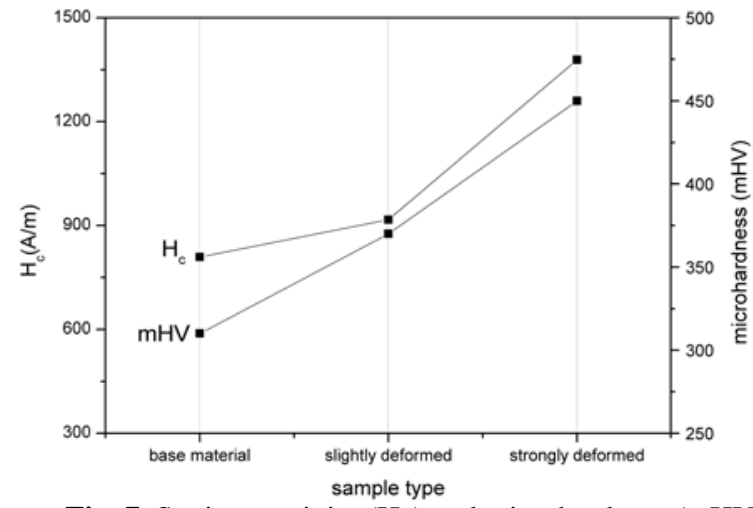

Fig. 7 Static coercivity (Hc) and microhardness (mHV) versus deformation state in a rail-material

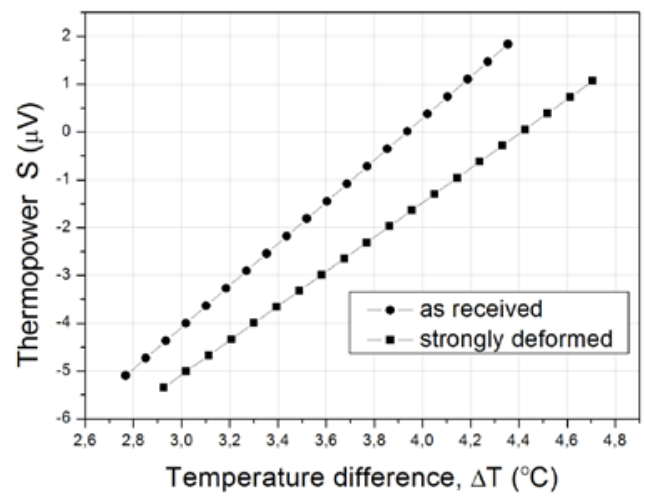

Fig. 8 Thermopower measured on rail-material samples with different deformation states 


\section{SUMMARY}

1. Simultaneous changes in microhardness, thermopower, as well as in coercivity were observed in the surface layer of carbon steel samples being previously subjected to rolling or sliding.

2. The observed changes are the consequence of increasing work -which was already developed in the period of plastic flow- and quench hardening.

3. In this level of "work hardening" crack formation cannot be detected in the samples, consequently a very early state of crack formation can be predicted by the outlined thermopower measurement.

\section{ACKNOWLEDGEMENTS}

The research presented in this paper was carried out within the scientific programme "Development of qualityoriented and harmonized $\mathrm{R}+\mathrm{D}+\mathrm{I}$ strategy and functional model at BME" project. This project is supported by the New Széchenyi Plan (Project ID: TÁMOP-4.2.1/B09/1/KMR-2010-0002).

This paper was developed within the project "Centre of Excellence for Integrated Research \& Exploitation of Advanced Materials and Technologies in Automotive Electronics” ITMS 26220120055.

\section{REFERENCES}

[1] SZABÓ, A. - BÁN, K. - JUHÁSZ, G. - NOVÁK, L. - LOVAS, A.: "A complex study of surface fatigue in carbon steels caused by rolling contact and sliding friction", $18^{\text {th }}$ International Conference of Applied Physics of Condensed Matter 2012 Strbske Pleso, Slovak Republic.

[2] DEBARBERIS, L. - ACOSTA, B. - BEERS, M. McGIRL, C. - SEVINI, F.: Experemintal Study of Irradiation Damage Effect by Steam Measurements. Proceedings of the 15th World Conference on NonDestructive Testing. October 15-21, 2000, Rome, Italy.

[3] BLATT, F. J. - SCHROEDLER, P. A. - FOILES, C. L.: Thermoelectric power of metals Premium press, New York and London.

[4] HOWSON, M. A. - GALLAGHER, B. L.: The electron transport properties of metallic glasses Volume 7 Number 5. December, 1988. Prplcm 170 (5) 265-324 (1988) North Holland-Amsterdam.

[5] PAL, Z. - TAKACS, J.: A thermopower and hardness measurements on steels, 12th International Conference on Applied physics of condensed matter June 21-23, 2006, Malá Lučivná, Slovakia, pp.: 348354.
[6] SZABO, A. - LOVAS, A.: Some basic observation and considerations for the thermopower measurements used as non-destructive material testing 25th International Colloquium of Advanced Manufacturing and Repair Technologies in Vehicle Industry, May, 2009. Balatonfüred, Hungary, pp.: 31-34, HU.

[7] SZABO, A. - LOVAS, A.: The role of surface and bulk structure on the thermopower characterization of perlitic carbon steels, 26 $6^{\text {th }}$ International Colloquium of Advanced Manufacturing and Repair Technologies in Vehicle Industry, May, 2010. Czestochowa, Poland.

[8] SZABÓ, A. - KOVAC, J. - LOVAS, A.: The contribution of chemical composition and the phase relation in the thermopower of $\mathrm{Fe}-\mathrm{Ni}$ alloys, $27^{\text {th }}$ International Colloquium of Advanced Manufacturing and Repair Technologies in Vehicle Industry, May, 2011. Svitavy, Czech Republic.

Received November 13, 2012, accepted February 8, 2013

\section{BIOGRAPHIES}

Antal Lovas was born in 1938, graduated in 1967 at Eötvös Lorand University as a chemist. He spent a year at FORTE in Vac in 1967 but still in this year he got a new position at the Central Pisician Research Institut, Department of Solid State Physics (MTA SZFKI). He was working in the field of unstable and glassy alloy systems and got his candidate degree in 1992. From 1994 he is working at the Budapest University of Technology and Economics, Department of Transportation Engineering, where he got his PhD. degree in 1999. Research area: physical metallurgy, solid state chemical reactions, $\mathrm{H}$ absorption in metals. Member of the Hungarian Academy of Sciences, Member of the Soft Magnetic Materials International Conference Organising Committee. Chairman of the SMM14 (Balatonfüred) Soft Magnetic Maerials International Conference Organising Committee.

Attila Szabo was born in 1982, graduated at Budapest University of Technology and Economics as a mechanical engineer in 2006. Right after finishing the university he got a position at a Hungarian company named Thales Nanotechnology Inc. as a junior development engineer. He was developing fuel cells and high pressure PEM Hgenerator cells of medical and chemical applications. In 2007 he got a position at UC Berkeley (USA) and spent a year in the field of microelectronic and micromechanic chip manufacturing. After his returning he got a position at the Budapest University of Technology and Economics as a teacher assistant. 